\title{
Ueber das Verhalten der Nerven zu den glatten Muskelfasern der Froschharnblase.
}

Von

\section{Dr. Tolotschinoff}

aus St. Petersburg.

Aus dem Institute für experimentelle Pathologie in Wien.

Die Froschharnblase bildet ein sehr geeignetes Object, um die in neuerer Zeit lebhaft besprochenen Beziehungen der Nerven zu den glatten Muskelfasern zu studiren. Ich wählte vorzugsweise junge Individuen von Rana temporaria aus, weil bei ihnen die Blase dünner und die einzelnen zu Bündeln angeordneten Muskelfasern nicht so dicht aneinander gedrängt sind, als bei rana escul. und daher viel leichter einer gründlichen Durchmusterung unterzogen werden können. Schneidet man die lebende Blase eines solchen Exemplars aus dem Körper aus, so contrahirt sie sich sehr lebhaft und bildet dadurch Falten, welche der Untersuchung hinderlich sind. Um dies zu vermeiden, schob ich ein gekrümmtes Glasrohr in die Kloake des Thieres und dehnte die Blase durch Einblasen von Luft möglichst stark aus. Die ausgedehnte Blase bepinselte ich solange mit $1 / 2 \%$ iger Lösung von Goldchlorid, bis die Muskelbündel weiss zu werden begannen. Nach diesem Zeichen ihres Absterbens waren die störenden Contractionen nicht mehr zu fürchten. Gewöhnlich genügte eine Zeitclauer von 10 Vinuten, um diese Erscheinung hervorzubringen. Alsdann schnitt ich die Blase aus dem Becken aus, brachte sie während weiterer 10 Minuten in eine gleich starke Lösung von Goldchlorid und dann in schwach angesäuertes Wasser und liess sie da drei Tage lang liegen. Während dieser Zeit färbte sich die Blase gewöhnlich dunkel violett. Dann spannte ich sie auf einer geeigneten Unterlage auf, entfernte mittelst Pinseln das Schleimhaut-Epithel und brachte einzelne Stücke in Glycerin auf das Objectglas. Sehr vor- 
theilhafte Bilder gewährten mir solche Blasenstücke, welche ich nach der Behandlung mit Goldchlorid in Carmin inbibirte. Es werden dadurch die Muskelelemente rosafarben, während die Nervenfasern ihre dunkelviolette Farbe beibehalten und sich dadurch von ersteren schärfer absetzen.

Die Muskeln der Blase ordnen sich zu grösseren und kleineren Bündeln, bilden, indem sie sich vielfach kreuzen, Maschen, durch welche übrigens noch einzelne, zuweilen verästigte Fasern durchgesteckt sind. Durch die Maschen hindurch ziehen die Blutgefässe und Nerven. Die letzteren erscheinen an mehreren Stellen als kleine Stämmchen, lösen sich bald in Fasern auf, welche sich ihrerseits dichotomisch theilen, häufig mit benachbarten Fasern anastomosiren und dadurch grössere und kleinere Maschen bilden. Die grösseren Maschen umspinnen die Muskeln, während die kleineren unter dem Epithel der Schleimhaut und demjenigen des Peritorium gelegen sind.

Da uns hier nur die Beziehungen der Nerven zu den Muskelfasern interessiren, so lassen wir ihr Verhalten $\mathrm{zu}$ den Gefässen und Epithelien ganz ausser Acht.

Die oben erwähnten mehrgestaltigen Nervenmaschen verlaufen entweder parallel den analog angeordneten Muskelbündeln oder kreuzen sich mit ihnen. Häufig sieht man Nerven von zwei entgegengesetzten Richtungen an die Muskelbündel herantreten und dann mit ihnen parallel verlaufen; zuweilen auch wieder abtreten, ohne mit ihnen eine sichtbare Beziehung einzugehen. Diejenigen Nerven aber, welche auf den Muskelfasern verbleiben, theilen sich dichotomisch und stellen so feinste Fädchen dar, welche ein sehr verschiedenes Verhalten zeigen. Ich sah dieselben über und unter dem Kerne in verschiedener Richtung hinwegziehen; jedoch konnte ich niemals Bilder sehen, wie sie Arnold ${ }^{1}$ ) in seiner bezüglichen Arbeit abbildet. Häufig sah ich diese feinsten Nervenfädchen dicht an den Contour eines Kernes angedrängt und sich da der Beobachtung entziehen; ein Verhalten, das mich veranlassen könnte, hier eine Endigung der Nervenfibrille an der Seite des Kernes zu vermuthen, wenn ich nicht bestimmt gesehen hätte, wie jene Fibrillen unter Umständen weiter gehen, um sich auf oder zwischen den Muskelfasern zu verlieren, so dass ich mir über ihre wirkliche Endigungsweise bis jetzt keine klare Vorstellung zu machen im Stande bin.

1) Stricker, Handbuch der Gewebelehre. 
Ueber d. Verhalt. d. Nerven z. d. glatten Muskelfas. d. Froschharnblase. 511

Schliesslich will ich noch erwähnen, dass ich ausser den bereits bekannten Kernanschwellungen im Verlaufe und an den Theilungsstellen der Nervenfasern noch Ganglienzellen mit grossen Kernen beobachtet habe, welche den Nervenstämmchen angelagert waren. 